\title{
Preparation of Biochars from Bio-Waste for Removing Pollutants from River Water
}

\author{
Yiyu $\mathrm{Wu}^{1} \&$ Xinhua $\mathrm{Xu}^{2}$ \\ ${ }^{1}$ Peddie School, New Jersey, USA \\ ${ }^{2}$ College of Environmental and Resource Science, Zhejiang University, Hangzhou, China \\ Correspondence: Xinhua Xu, College of Environmental and Resource Science, Zhejiang University, Hangzhou, \\ No. 866 Yuhangtang Road, China. Tel: 86-571-8898-2031. E-mail: xuxinhua@zju.edu.cn
}

\author{
Received: July 14, 2018 \\ Accepted: July 27, 2018 \\ Online Published: August 28, 2018 \\ doi:10.5539/esr.v8n1p12 \\ URL: https://doi.org/10.5539/esr.v8n1p12
}

\begin{abstract}
As a low-cost adsorbent, biochar can be used as a great tool for water treatment. Instead of using expensive woody biomass for biochar production, this study aimed to investigate the feasibility of using biowaste such as sugarcane skins, orange peels, and peanut shells to produce biochars through pyrolysis at $700^{\circ} \mathrm{C}$. The optimal time length, dosage, and temperature for water purification were explored afterwards in batch tests. The ammonia nitrogen $\left(\mathrm{NH}_{4}{ }^{+}-\mathrm{N}\right)$ removal efficiencies of sugarcane skin, orange peel, and peanut shells were $74.4 \%, 96.3 \%$ and $90.8 \%$, respectively, and the simultaneous permanganate index removal efficiencies were $26.6 \%, 31.0 \%$ and $26.6 \%$, respectively. There was no significant difference in $\mathrm{NH}_{4}{ }^{+}-\mathrm{N}$ and permanganate index removal efficiencies when the dosage of three kinds of biochars was higher than $1.0 \mathrm{~g} / 100 \mathrm{ml}$ water. Greater adsorption capacity of biochars was observed for pollutants when temperature was increased from 10 to $30^{\circ} \mathrm{C}$. These results confirmed our assumption that biowaste could make for good raw materials in producing biochars.
\end{abstract}

Keywords: biochars, shells, COD removal, ammonia nitrogen

\section{Introduction}

The tremendously fast growth of the urban populations and the expansion of urban construction in China, along with the discharge of sewage and waste into river waters, have deteriorated Chinese river water quality, which has posed increasing risks to aquatic ecosystems. Finding a method to economically remove the pollutants from river water is a great challenge (Ternes, 2007; Rozic et al., 2000).

Among many approaches, adsorption of contaminants by using activated carbon is a well-developed and effective technique for water purification. Compared with expensive activated carbon, biochar prepared by biomass also has a greater surface area due to its high porosity, which make it a low-cost and high-efficiency adsorbent for water treatment (Kumar et al., 2010; Pajooheshfar et al., 2009). Commercially available biochar is commonly made from woody biomass and its high cost limits its wide application. Therefore, low-cost materials for biochar production need to be explored. Converting biowaste into biochar has the potential to not only eliminate the amount of pollutants in water bodies, but also to solve the problem of the household waste disposal. (Issabayeva et al., 2010; Rosenfeld and Henrry, 2001). Some biowaste consists largely of stabile carboniferous substance which can serve as promising raw materials for biochar production. This study aimed to investigate the potential production of biochars through pyrogenic decomposition by using sugarcane skin, orange peels, and peanut shells as biomass materials. We also investigated the removal of water- pollutants using the biowaste derived biochars produced.

\section{Materials and Methods}

\subsection{Preparation of Biochars from Sugarcane Rind, Orange Peel and Peanut Shells}

Pyrogenic decomposition was conducted to produce biochars from the biowastes. Sugarcane rind, orange peel, and peanut shells were selected, cut into small pieces of approximately $0.3 \mathrm{~cm} \times 0.5 \mathrm{~cm}$, and dried in an oven at $50^{\circ} \mathrm{C}$ for 20 hours. About $15 \mathrm{~g}$ each of dried sugarcane rind, orange peel and peanut shells were placed in a vacuum tube furnace. The temperature increased at a rate of $5^{\circ} \mathrm{C} / \mathrm{min}$ to $700^{\circ} \mathrm{C}$ and remained stable for 0.5 hours for carbonization under the protection of nitrogen gas. The experimental apparatus is shown in Figure 1. Generated biochar samples were weighed after carbonization. 


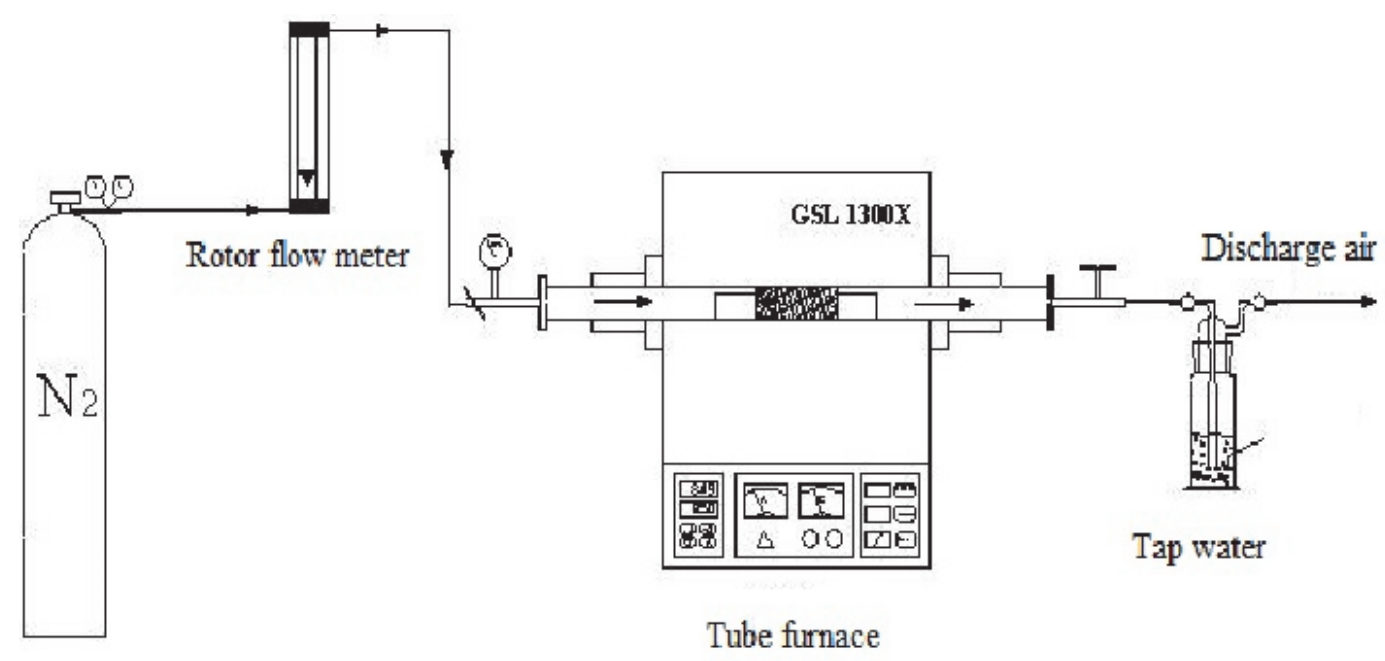

Figure 1. Apparatus for preparing biochars

\subsection{Removing Pollutants Using Biochars}

Batch tests were performed to explore the performance of generated biochars. An aliquot of $300 \mathrm{~mL}$ of water sampled from a local river in East Hangzhou (Zhejiang Province, China) was put into three 250-ml Erlenmeyer flasks, and various dosages $(0.5,1,1.5$ and $2.0 \mathrm{~g} / 100 \mathrm{~mL})$ of biochars made from sugarcane rind, orange peel or peanut shells were added to flasks with the river water. The Erlenmeyer flasks were placed in a temperature controlled shaker for 9 hours at $200 \mathrm{rpm}$. Water samples $(5 \mathrm{ml})$ were collected every hour during the 9 hours, and then filtered through filter membranes with pore size of $0.22 \mu \mathrm{m}$ and then tested immediately. $\mathrm{NH}_{4}^{+}-\mathrm{N}$ and permanganate indexes were tested to track changes in the concentration of $\mathrm{NH}_{4}{ }^{+}-\mathrm{N}$ and organic matters in the water during the adsorption process.

\subsection{Analysis and Calculations}

Surface morphologies of sugarcane rind, orange peel and peanut shells were characterized by using a scanning electron microscope (Philips XL30ESEM, the Netherlands) before and after carbonization at the Analysis and Testing Center of Zhejiang University. The permanganate index was determined by using the acidity method, and the $\mathrm{NH}_{4}{ }^{+}-\mathrm{N}$ concentration were determined by using Nessler's reagent spectrophotometric method.

\section{Results and Discussion}

\subsection{Morphology Changes of Sugarcane Rind, Orange Peel and Peanut Shells before and after Pyrogenic Decomposition}

To understand changes in surface morphology of sugarcane rind, orange peel and peanut shells before and after pyrogenic decomposition, we employed a scanning electron microscopy (SEM) for characterization (Figure 2). According to the images, the morphology of the raw materials changed and rendered high porosities. During pyrolysis and carbonization, the biomass in biochars decomposed and reacted with active agents such as water vapor, carbon dioxide, forming a large number of micro pores. The biochars that developed the most micropores have large specific surface area, high porosity and superior adsorption capacity (El-Hendawy et al., 2008). Previous studies have shown that remarkable improvements regarding specific surface area, total specific pore volume, microporous volume, average pore size and cation exchange capacity occur when the burning temperature is above critical temperature $\left(700^{\circ} \mathrm{C}\right)$ (Nguyen et al., 2004; James et al., 2005; Lehmann and Joseph, 2009). 


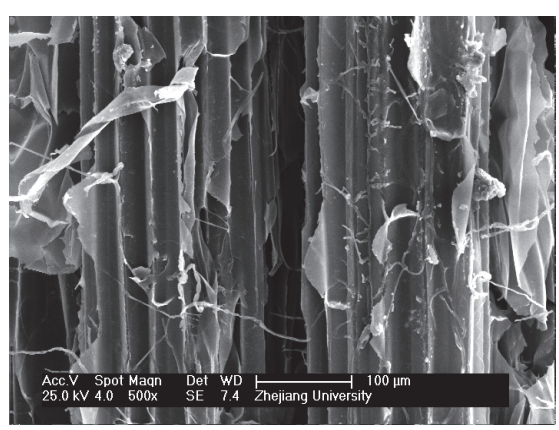

(a) Sugarcane rind before carbonization $(500 \times)$

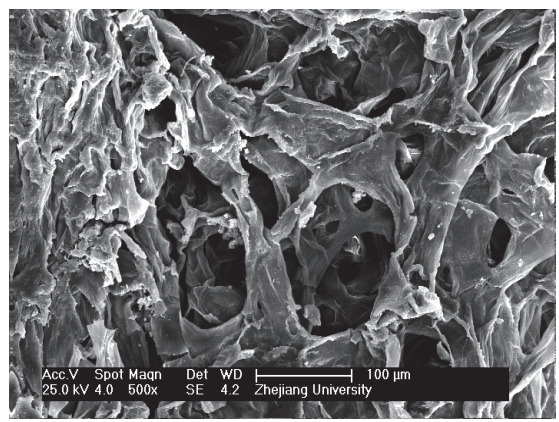

(c) Orange peel before carbonization $(500 \times)$

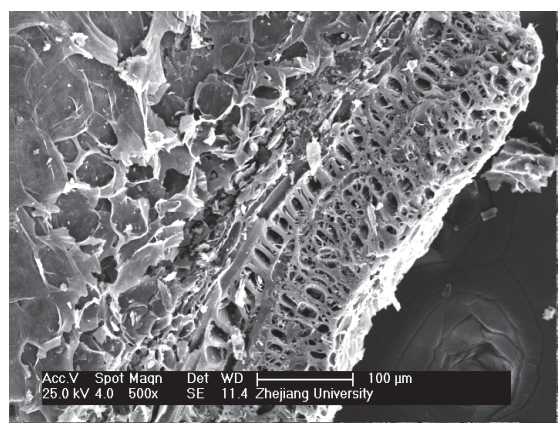

(e) Peanut shell before carbonization $(500 \times)$

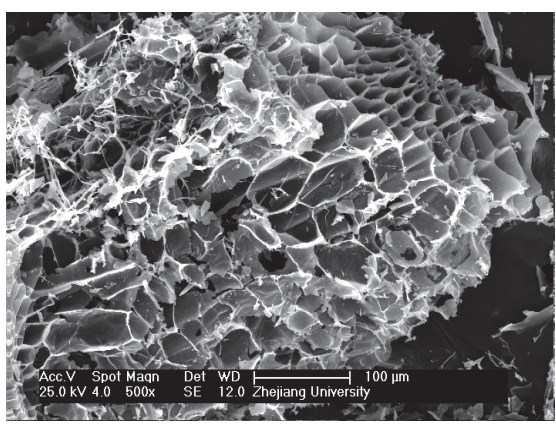

(b) Sugarcane rind char after carbonization $(500 \times)$

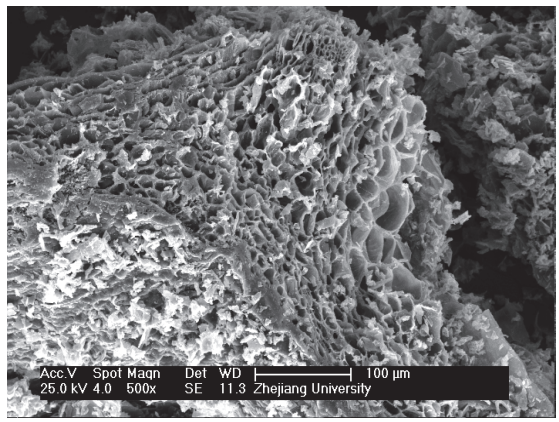

(d) Orange peel char after carbonization $(500 \times)$

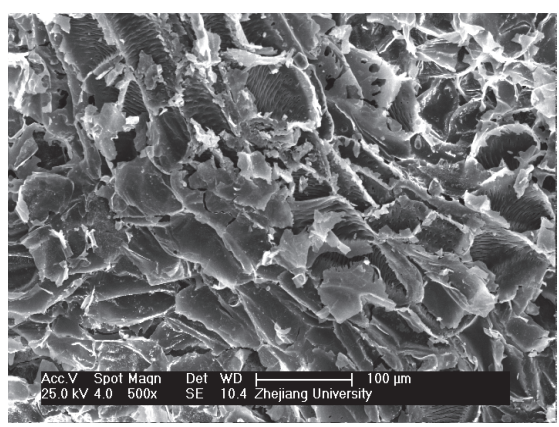

(f) Peanut shell char after carbonization $(500 \times)$

Figure 2. Scanning electron microscopic images before and after preparing biochars

\subsection{Pollutant Removal Using Biochars}

\subsubsection{Effect of Treatment Time}

To determine the optimal water treatment duration using biochars made from sugarcane rind, orange peel and peanut shells, samples were collected on an hourly basis during the 9-h test. Changes in the concentrations of $\mathrm{NH}_{4}{ }^{+}-\mathrm{N}$ and permanganate index of the water are shown in Figure 3. 

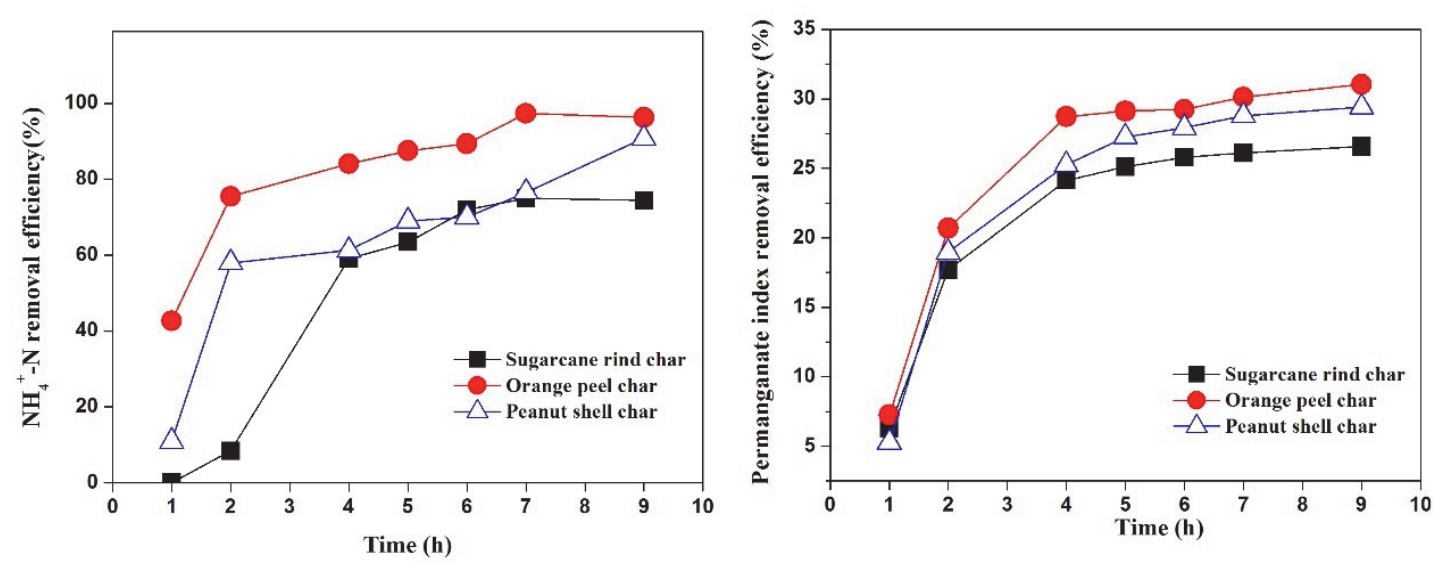

Figure 3. $\mathrm{NH}_{4}{ }^{+}-\mathrm{N}$ and organic matters removal efficiencies by the biochar made from sugarcane rind, orange peel and peanut shells over time

(Dosage: $1 \mathrm{~g}$; reaction temperature: $30^{\circ} \mathrm{C}$ )

As shown in the Figure 3, the removal efficiencies of $\mathrm{NH}_{4}{ }^{+}-\mathrm{N}$ by the three types of biochars increased as the reaction proceeded. The adsorption rates of the three types of biochars in the first 2 hours were higher than that in the rest of the time. The $\mathrm{NH}_{4}{ }^{+}-\mathrm{N}$ removal efficiencies after $9 \mathrm{~h}$ by the biochars made from sugarcane rind, orange peel and peanut shells were $74.4 \%, 96.3 \%$ and $90.8 \%$, respectively. Unlike the $\mathrm{NH}_{4}^{+}-\mathrm{N}$ removal efficiencies, the decrease of permanganate indexes by biochars was comparatively lower, and the removal efficiencies of organic matter by the biochars made from sugarcane rind, orange peel and peanut shells were $26.6 \%, 31.0 \%$ and $29.4 \%$ after $9 \mathrm{~h}$ of reaction, respectively. The adsorption equilibrium was reached after approximately $4 \mathrm{~h}$ of reaction for the three types of biochars. As seen in figure 3, the organic matter and $\mathrm{NH}_{4}{ }^{+}-\mathrm{N}$ removal efficiencies by the biochars made of orange peel were greater than that by the biochars made of sugarcane rind and peanut shells.

The results of study by Shaaban and Dimin (2004); Chia et al., (2014); Ahmad et al., (2014) show that there are many oxygen-containing functional groups on the biochar surface, such as hydroxyl group, carboxyl group and sulfonic acid group, which contribute to ammonia removal. In addition, biochars have a large amount of negative charges and high charge density which also benefit the superior removal of ammonia. It was reported that the organic matter removal by biochars is caused by the combination of adsorption and partitioning (Chen et al., 2008; Han et al., 2016). Most biochar contains positive and negative ion on its surface, and has a high capacity of ion exchange. Given that the $\mathrm{NH}_{4}{ }^{+}-\mathrm{N}$ removal by biochars was obviously better than that of organic matter, ion exchange might play a leading role.

\subsubsection{Effect of Dosage on Pollutant Removal}

To determine the optimal dosage for treating polluted river water with the biochars made of sugarcane rind, orange peel and peanut shells, $0.5,1.0,1.5$ or $2.0 \mathrm{~g}$ of biochars was added into every $100 \mathrm{ml}$ of water, respectively, and the reaction time was set as $6 \mathrm{~h}$. The results regarding ammonia and organic removal under different biochar doses are shown in Figure 4. 

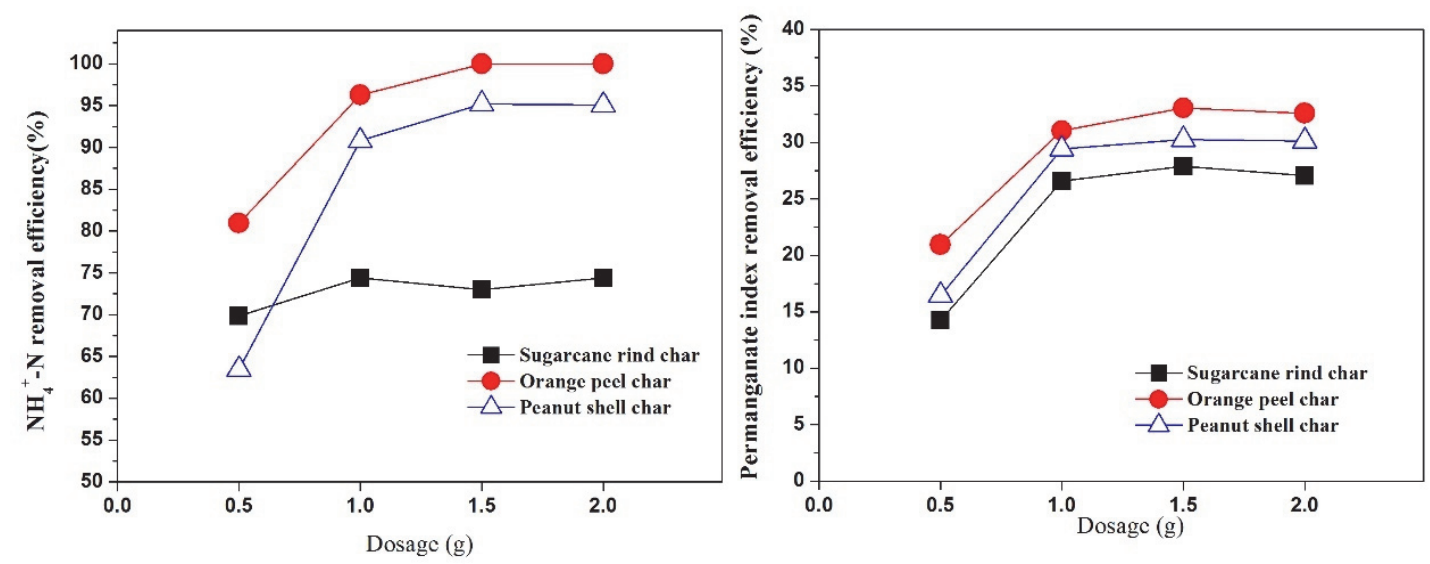

Figure 4. $\mathrm{NH}_{4}{ }^{+} \mathrm{N}$ and organic matters removal efficiencies by the biochars made from sugarcane rind, orange peel and peanut shells at different dosages

(Reaction time: $9 \mathrm{~h}$, reaction temperature: $30^{\circ} \mathrm{C}$ )

As seen in Figure 4, with the increasing doses of biochars from $0.5 \mathrm{~g}$ to $1.0 \mathrm{~g}$, the $\mathrm{NH}_{4}{ }^{+}-\mathrm{N}$ and organic matter removal efficiencies also significantly increased, but further increased biochar dose had no significant effect on the removal of $\mathrm{NH}_{4}{ }^{+} \mathrm{N}$ or permanganate index. Therefore, under the experimental conditions, the optimal dosage of $1.0 \mathrm{~g}$ biochar $/ 100 \mathrm{ml}$ water was selected for the treatment of river water. It was also observed that adsorption processes with all three types of biochars displayed similar patterns. The removal rates increased with the increasing biomass dosage, which is consistent with other previous studies (El-Sikaily et al., 2011; Hussain et al., 2006). The improved performance with high dosage is mainly attributed to the increased adsorbent surface area.

\subsubsection{Effect of Temperature on Pollutant Removal}

To determine the optimal temperature for treating the polluted water with the biochars made from sugarcane rind, orange peel and peanut shells, the adsorption processes under the temperature of 10,20 , or $30^{\circ} \mathrm{C}$ were investigated. After $6 \mathrm{~h}$, samples were collected to measure the changes in the $\mathrm{NH}_{4}{ }^{+}-\mathrm{N}$ and permanganate index of the water.
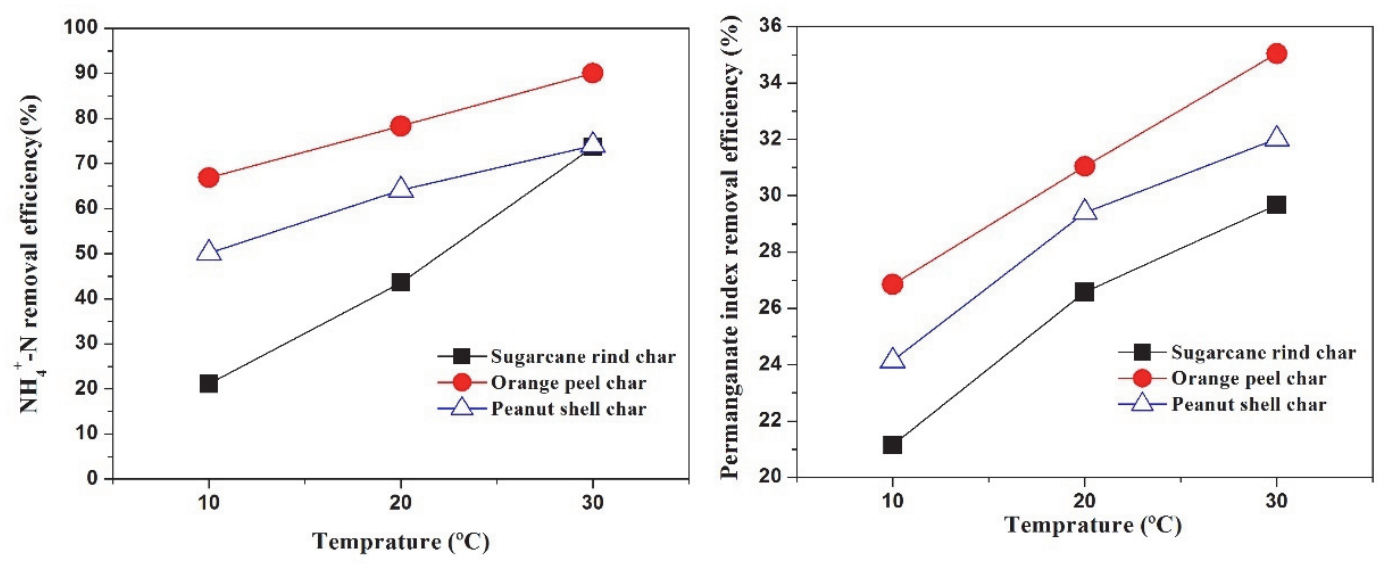

Figure 5. Removal efficiency of $\mathrm{NH}_{4}{ }^{+} \mathrm{N}$ and organic matters by the biochars made from sugarcane rind, orange peel and peanut shells at different temperatures

(Reaction time: $6 \mathrm{~h}$; dosage: $1.0 \mathrm{~g} / 100 \mathrm{ml}$ water)

As seen in Figure 5, the removal efficiencies of pollutants by three types of biochars increased with increasing temperature. The higher the temperature, the greater the adsorption rates of $\mathrm{NH}_{4}{ }^{+}-\mathrm{N}$ and organic matter. Therefore, high temperatures in the summer could provide more favorable conditions for treating river water using biochars. 
When the temperature was $40^{\circ} \mathrm{C}$, the $\mathrm{NH}_{4}{ }^{+}-\mathrm{N}$ removal efficiencies by the biochars made of sugarcane rind, orange peel and peanut shells were $73.7 \%, 90.0 \%$ and $74.0 \%$, respectively, and the removal efficiencies of the permanganate index were comparatively lower: $29.7 \%, 35.0 \%$ and $32.0 \%$, respectively. The organic matter and $\mathrm{NH}_{4}{ }^{+} \mathrm{N}$ removal efficiencies by the biochars made of orange peel were higher than that by the biochars made of sugarcane rind and peanut shells.

\section{Conclusion}

Results suggest that biochars made from sugarcane rind, orange peel and peanut shells are promising adsorbents for water purification on a large scale. Under the same conditions, the permanganate index and $\mathrm{NH}_{4}{ }^{+}-\mathrm{N}$ removal efficiencies by the biochars made of orange peel are higher than those by the biochars made of sugarcane rind and peanut shells. Under experimental conditions, the optimal dosage of biochars was $1.0 \mathrm{~g}$ for $100 \mathrm{~mL}$ of river water, and $30^{\circ} \mathrm{C}$ was the best temperature for removal. Using the biochars made of biowaste as adsorbents to purify water could not only reduce domestic solid waste, but could also provide a low-cost approach to treating polluted river water.

\section{Acknowledgement}

The author would like to thank Shen Yanhong and Zhang Mingjie for the help in the preparation of biochar.

\section{References}

Ahmad, M., Rajapaksha, A. U., \& Lim, J. E. (2014). Biochar as a sorbent for contaminant management in soil and waste: A review. Chemosphere, 99, 19-33. https://doi.org/10.1016/j.rser.2017.05.057

Chen, B., Zhou, D., \& Zhu, L. (2008). Transitoinal adsorption and partition of nonpolar and polar aromatic contaminants by biochars of pine needles with different pyrolytic temperatures. Environ. Sci. Technol, 42, 5137-5143. https://doi.org/10.1021/es8002684

Chia, C. H., Singh, B. P., \& Joseph, S. (2014). Characterization of an enriched biochar. Journal of Analytical and Applied Pyrolysis, 108, 26-34. https://doi.org/10.1016/j.jaap.2014.05.021

El-Hendawy, A. N. A., Alexander, A. J., \& Andrews R. J. (2008). Effects of activation schemes on porous, surface and thermal properties of activated carbons prepared from cotton stalks. Journal of Analytical and Applied Pyrolysis, 82(2), 272-278. https://doi.org/10.1016/j.jaap.2008.04.006

El-Sikaily, A., Nemr, A. E., \& Khaled, A. (2011). Copper sorption onto dried red alga pterocladia capillacea and its activated carbon. Chem. Eng, 168, 707-714. https://doi.org/ 10.1016/j.cej.2011.01.064

Han, L., Ro, K. S., Sum, K., Sum, H., Wang, Z., Libra, J. A., \& Xing, B. (2016). New evidence for high sorption capacity of hydrochar for hydrophobic organic pollutants. Envrion. Sci. Technol, 50, 13274-13282. https://doi.org/10.1021/acs.est.6b02401

Hussain, S., Aziz, H. A., Isa, M. H., Adlan, M. N., \& Asaari, F. A. H. (2006). Physico-chemical method for ammonia removal from synthetic wastewater using limestone and GAC in batch and column studies. Bioresour. Technol, 98, 874-880. https://doi.org/10.1016/j.biortech.2006.03.003

Issabayeva, G., Aroua, M. K., \& Sulaiman, N. M. (2010). Study on palm shell activated carbon adsorption capacity to remove copper ions from aqueous solutions. Desalination, 262, 94-98. https://doi.org/10.1016/j.desal.2010.05.051

James, G., Sabatini, D. A., \& Chiou, C. T. (2005). Evaluation phenanhrene sorption on various wood char. Water Res., 39, 549-559. https://doi.org/10.1016/j.watres.2004.10.015

Kumar, R. A., Velayudhan, K. T., Ramachandran, V., Bhai, R. S., Unnikrishnan, G., \& Vasu, K. (2010). Adsorption and removal kinetics of phosphonate from water using natural adsorbents. Water Environ. Res., 82, 62-68. https://doi.org/10.2175/106143009X447939

Lehmann, J., \& Joseph, S. (2009). Biochar for environmental management, science and technology. London: Earthscan, 1-12.

Nguyen, T. H., Brown, R. A., \& Ball W. P. (2004). An evaluation of thermal resistance as a measure of black carbon content in diesel soot, wood char, and sediment. Organic Geochem, 35, 217-234. https://doi.org/10.1016/j.orggeochem.2003.09.005

Pajooheshfar, S. P., \& Saeedi, M. (2009). Adsorptive removal of phenol from contaminated water and wastewater by activated carbon, almond, and walnut shells charcoal. Water Environ. Res., 81, 641-648. https://doi.org/10.2175/106143008X390780 
Rosenfeld, P. E., \& Henrry, C. L. (2001). Activated carbon and wood ash sorption of wastewater, compost, and biosolids odorants. Water Environ. Res., 73, 388-393. https://doi.org/10.2175/106143001X139425

Rozic, M., Cerjan-Stefanovic, S., Kurajica, S., Vancina, V., \& Hodzic, E. (2000). Ammoniacal nitrogen removal from water by treatment with clays and zeolites. Water Res., 34, 3675-3681. https://doi.org/10.1016/S00431354(00)00113-5

Shaaban, A., Se, S., \& Dimin, M. F. (2014). Influence of heating temperature and holding time on biochars derived from rubber wood sawdust via slow pyrolysis. Journal of Analytical and Applied Pyrolysis, 107, 3139. https://doi.org/10.1016/j.jaap.2014.01.021

Tan, X., Liu, Y., Zeng, G., Wang, X., Hu, X.J., Gu, Y.L., Yang, Z.Z. (2015). Application of biochar for the removal of pollutants from aqueous solutions. Chemosphere, 125, 70-85. https://doi.org/10.1016/j.chemosphere.2014.12.058

Ternes, T. (2007). The occurrence of micopollutants in the aquatic environment: a new challenge for water management. Water Sci. Technol, 55(12), 327. https://doi.org/10.2166/wst.2007.428

\section{Copyrights}

Copyright for this article is retained by the author(s), with first publication rights granted to the journal.

This is an open-access article distributed under the terms and conditions of the Creative Commons Attribution license (http://creativecommons.org/licenses/by/4.0/). 